\title{
COVID-19: A Global Emergency
}

\author{
Cheryl Ann Alexander ${ }^{1}$ and Lidong Wang ${ }^{2 *}$ \\ ${ }^{1}$ Institute for IT innovation and Smart Health, Mississippi, USA \\ ${ }^{2}$ Institute for Systems Engineering Research, Mississippi State University, Mississippi, USA
}

Corresponding author: Lidong Wang, Institute for Systems Engineering Research, Mississippi State University, Mississippi, USA

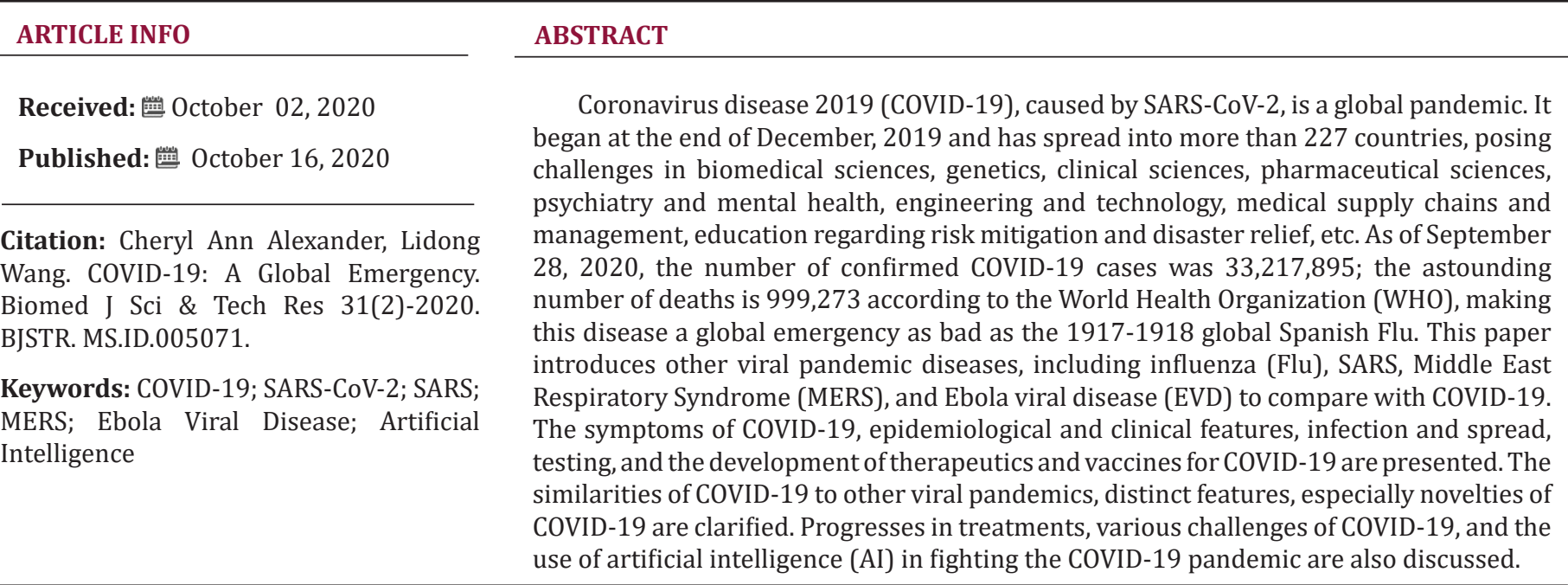

\section{Introduction}

The most common causes of death due to COVID-19 are related to the lungs, kidneys, and the heart. Severe COVID-19 can cause heart failure, regardless of the patient's past cardiac history [1]. Coronaviruses (CoVs) are classified into four types: $\alpha, \beta, \gamma$, and $\delta$. Phylogenetical analysis revealed that SARS-CoV-2 is a lineage B $\beta-\operatorname{CoV}[2,3]$. CoVs have at least four structural proteins: Spike (S), Nucleocapsid (N), Membrane (M), and Envelope (E). S facilitates host attachment, entrance, and virus-to-cell membrane fusion during infection. S glycoproteins foster entry into cells and SARSCoV-2 S utilizes the angiotensin-converting enzyme II (ACE2) to enter cells $[4,5]$. Viral infectivity relies on interactions between the virus envelope and components of the host cell's plasma membrane. It has also been demonstrated that certain molecules can decrease the infectivity of some CoVs [6]. COVID-19 can be regarded as an issue of One Health, which is an approach that attempts to strategize coordinated efforts of multiple disciplines, including environmental health and environmental surveillance [7]. The relationship between COVID-19 cases and meteorological factors in 30 Chinese provincial capitals was studied by scholars.
A daily dataset was compiled, including confirmed cases, absolute humidity, diurnal temperature range, ambient temperature, and migration scale index for every provincial capital. Meteorological factors were discovered to have independent effects on the transmission of the disease, while weather with a low humidity, a low temperature, and a mild diurnal temperature range facilitates COVID-19 transmission [8].

Infectious diseases are rapidly spread by national and international travel. Respiratory droplets infected with viral material can cause surface contamination when the virus settles on hard surfaces such as plastic, cardboard, metal, etc., called fomites, and is often present on various sites and subjected to touch many times daily, indicating a possible risk in some airport sites, schools, businesses, etc. Among tested surfaces, plastic trays in the security screening area seemed to have the greatest probability of risk and managing the risk is nearly impossible as infection from touching these surfaces is almost unavoidable for boarding passengers. Symptomatic or asymptomatic respiratory tract infection of passengers infected with COVID-19 could be frequent with possible 
transmission to other passengers via multiple transmission modes (such as droplet and contact) during travel or when arriving at the destination [9]. The main purpose of this paper is to explore COVID-19, including its features, progress in therapeutics, testing, and challenges facing healthcare providers and experts. Many people are unaware of the risk of infection, in part due to some similarities to other viral diseases such as influenza, MERS, SARS, and EVD. Some health experts have even gone so far as theorizing that prior exposure to SARS has increased immunity in some populations. Therefore, these viral diseases are also introduced in comparison with COVID-19. The similarities of COVID-19 to these other viral diseases are presented and distinct features and novelties of COVID-19 are explored.

\section{Influenza}

Influenza (Flu) can cause an acute respiratory illness. Categorized into three types: A, B, and C, influenza A and influenza $B$ can cause seasonal epidemics, while influenza $C$ often causes mild disease. The H1N1pdm09 virus cocirculated with the H3N2 and influenza B viruses during the 2015-2016 flu season; over $50 \%$ of the cases reported to the Centers for Disease Control and Prevention (CDC) were caused by H1N1 [10]. The pandemic potential and transmissibility of flu viruses relies on their ability to efficiently replicate, retaining viability when being released from a host with infection and maintaining virility while passing through the environment, and initiating new infection in the next host [11]. Conventional flu vaccines are developed to stimulate neutralizing antibodies against the immunodominant, while inherent limitations including a lack of protection from an antigenically novel pandemic flu and suboptimal protection from rapidly changing seasonal flu viruses. New technology for developing flu vaccines has focused on aiming conserved antigens and stimulating a cross-reactive $\mathrm{T}$ cell response [12]. Influenza viruses may also mutate, which can possibly reduce the effectiveness of the vaccines. The efficacy of a flu vaccine may rely on factors such as drift, underlying medical condition, patient's age, and any medications leading to immunosuppression [13]. Next-generation sequencing (NGS) facilitates a more efficient response to the flu, because NGSs can be employed to identify drug resistant mutations in clinical flu virus isolates [14].

\section{SARS and MERS}

A SARS outbreak occurred in the winter of 2002 to 2003 in China, then spreading to Hong Kong, Vietnam, Singapore, Canada, etc. $[15,16]$. SARS causes a life-threatening pneumonia, caused by SARS-CoV-1 which is characterized by human-to-human transmission; in recent years there have been several explosive outbreaks. The rapid transmission by highly infectious respiratory aerosols, droplets, and transmission via the orofecal route have caused a high mortality for infected cases, making SARS a global threat $[17,18]$. The epidemiological features of SARS-CoV-1 at first suggested that SARS transmission was through airborne transmission via large respiratory droplets and but the orofecal route through contact with humans and surfaces contaminated with SARS-CoV-1 cannot be rule out. While most cases were the direct human-to-human transmission through respiratory droplets, other modes of transmission have also been discovered. Fecal shedding in patients with SARS is frequent and has led to an outbreak in Hong Kong. The spread pattern of SARS related to sick patients who travel on airplanes has demonstrated that airborne transmission can also happen during a flight $[18,19]$. There is no certified vaccine or specific antivirals for SARS. The outbreak of SARS from 2002 to 2003 was controlled using traditional methods, such as patient isolation, travel restrictions, therapeutic treatments, etc. [20].

MERS coronavirus (MERS-CoV) enters the human population through indirect or direct contact with infected dromedary camels as well as infected persons [21]. The single-humped, Arabian dromedary camel has been strongly implicated as the MERS-CoV reservoir in which the disease is either asymptomatic or manifested as a mild respiratory infection. High seropositivity rates of MERS$\mathrm{CoV}$ were detected in dromedaries from many African and Arabian countries. MERS-CoV causes a severe respiratory infection, possible renal failure, and potentially multiorgan damage in infected patients [22]. MERS-CoV can also be transmitted through airborne particles; human-to-human transmission occurs primarily through the inhalation of infectious respiratory droplets or via direct contact with an infected patient. Indirect transmission can also occur via contaminated items, e.g., devices, equipment, and surfaces. A large viral load of MERS-CoV was found in the fecal samples of certain types of bats, but the bats tested were different from the types in Saudi Arabia where the MERS outbreak happened [23]. There are no certified antiviral therapeutics or vaccines for MERS and management is chiefly supportive based on the patient's clinical condition [24]. Climate factors affect MERS with an increase in cases from April to August. A low relative humidity, low wind speed, high temperature, and high ultraviolet index can help increase the number of MERS cases. Climate conditions should be assessed in community settings and hospitals, incorporated into policies and guidelines as a source or measure for prevention, and used for the control and elimination of the infection risk [25]. MERS is still in the WHO list of possible major pandemics, and issues regarding pathogenesis, epidemiology, control, and management need to be addressed. A joint international response plan for MERS-CoV is essential for better coordination and collaboration [26].

\section{EBOLA Viral Disease}

Ebola viral disease (EVD) is caused by the Ebola virus (EBOVs). EVD has occurred mainly in West and Sub-Saharan Africa since it emerged in 1976 [27]. However, other countries have experienced outbreaks of EVD because many healthcare workers travel to Africa to assist in caring for patients afflicted with EVD. In the USA, some cases had developed earlier in the prior decade when caregivers 
traveled home from Africa, infected by patients there. The symptoms of EVD include high fevers, arthralgia, severe fatigue; hemorrhagic manifestations such as oozing and acute bleeding occur in the final stages [28]. Ironically, EVD can also cause a "cytokine storm" and resulting pneumonias and microthrombi disease like SARS-CoV-2. The "cytokine storm" can result in a fatal respiratory depression, a need for mechanical ventilation, and sequalae associated with the microthrombi. The 2014-2016 outbreak of EVD in West Africa is the largest recorded EVD outbreak [29]. The detection of viral ribonucleic acid based on polymerase chain reaction (RT-PCR) is a standard for testing EBOVs [30]. According to the CDC, EVD is most often $80 \%$ fatal. There are no approved therapeutics for EVD or post-Ebola syndrome. Patients in treatment can get discouraged due to the low survival rate of EVD and because EVD carries such a risk of contact infection and has such a low survival rate, healthcare workers are also reluctant to take care of patients with EVD. There has been a considerable amount of research work conducted in the development of vaccines and antivirals or antibody preparations [31]. Micronutrient supplementation has also been suggested for the care of EVD. Early supplementation of multivitamins can help lower overall mortality. An ordinary component of supportive care for EVD is micronutrients. When there is a micronutrient deficiency, international guidelines call for supplementation which includes taking multivitamins [32].

\section{SARS-CoV-2 or COVID-19}

SARS-CoV-2 and Disorders Due to COVID-19: It has been theorized that SARS-CoV-2 was possibly transmitted to humans from bats or an undecided intermediate animal host [33]. It is $96 \%$ identical to a bat coronavirus at the whole-genome level [34]. Its viral pathogenesis has not been confirmed, but sequencebased analysis has indicated that bats should be a key reservoir. Studies have shown that SARS-CoV-2 utilizes the ACE2 as a cellular entry receptor $[2,3,35]$. COVID-19 can lead to the respiratory and systemic disorders shown in Figure 1 [36].

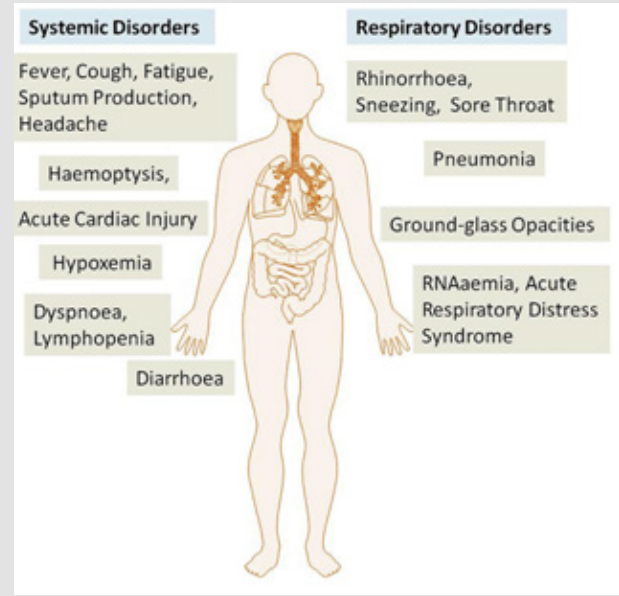

Figure 1: Systemic and respiratory disorders due to COVID-19 infection.

\section{Clinical and Epidemiological Characteristics of COVID-19 Compared to Other Viral Diseases}

There are some similarities and distinct comparisons between COVID-19 and other viral diseases such as influenza, SARS, and MERS. Table 1 [37] lists the incubation and virus family of each viral disease. Differences between MERS-CoV, SARS-CoV-1, and SARS-CoV-2 in some epidemiological features are shown in Table 2 [38]. $R_{0}$ is the basic reproduction number and it is also called the basic reproductive ratio. Clinical data collected from 31 provinces in China indicate that SARS-CoV-2 and SARS-CoV-1 have some common clinical features, which are shown in Table 3 [39]. It is noteworthy that only $43.8 \%$ of patients had a fever on initial manifestation.

Table 1: The incubation and virus families of various viral diseases.

\begin{tabular}{|c|c|c|}
\hline Virus (Disease) & Virus Family & Incubation \\
\hline Influenza A (Seasonal flu) & Orthomyxovirus & 2 days \\
\hline H1N1 Influenza A (swine flu) & Orthomyxovirus & $1-4$ days \\
\hline MERS-CoV (MERS) & Coronavirus & $1.9-14.7$ days \\
\hline SARS-CoV-1 (SARS) & Coronavirus & $2-7$ days \\
\hline SARS-CoV-2 (COVID-19) & Coronavirus & $2-14$ days \\
\hline
\end{tabular}

Table 2: Some epidemiological features of MERS-CoV, SARSCoV-1, and SARS-CoV-2.

\begin{tabular}{|c|c|c|c|}
\hline Features & MERS-CoV & SARS-CoV-1 & SARS-CoV-2 \\
\hline Median Incubation (days) & 5.2 & 4.6 & 6.4 \\
\hline Case-fatality rate (\%) & 34 & 9.6 & $\begin{array}{c}3-3.5 \\
\text { (estimate of } \\
\text { the average } \\
\text { value) }\end{array}$ \\
\hline $\begin{array}{c}\text { Case fatality rate with } \\
\text { comorbidities (\%) }\end{array}$ & 60 & 46 & 73.3 \\
\hline Estimated R & $<1$ & $2.0-5.0$ & $2.3-5.5$ \\
\hline Serial interval (days) & 12.6 & 8.4 & $2.6-7.5$ \\
\hline Long period of infectivity & No & No & Yes \\
\hline Asymptomatic viral load & Less & Less & High \\
\hline
\end{tabular}

Table 3: Clinical features of patients with SARS-CoV-1 and patients with SARS-CoV-2.

\begin{tabular}{|c|c|c|}
\hline Features & SARS-CoV-1 & SARS-CoV-2 \\
\hline Fever & $99-100 \%$ & $\begin{array}{c}87.9 \% \text { (initial: } \\
43.8 \% \text { ) }\end{array}$ \\
\hline Nonproductive cough & $25 \%-75 \%$ & $67.7 \%$ \\
\hline Fatigue & $38.1 \%$ & $31.2 \%$ \\
\hline Dyspnea & $40-42 \%$ & $18.6 \%$ \\
\hline Headache & $35.4 \%-55.8 \%$ & $13.6 \%$ \\
\hline Chills & $27.8 \%-73.2 \%$ & $11.4 \%$ \\
\hline Nausea or vomiting & $19.4 \%-19.6 \%$ & $5.0 \%$ \\
\hline Nasal congestion & $2.1 \%$ & $4.8 \%$ \\
\hline Diarrhea & $20-25 \%$ & $3.7 \%$ \\
\hline
\end{tabular}




\section{Infection and Spread of COVID-19}

Age and the presence of comorbid illnesses increase the risk of death among patients with COVID-19 [40]. Besides the usual mechanisms by which diabetes can predispose a patient to infection, a few factors are related to an increase of risk or severity of infection with SARS-CoV-2:

a) The increase of Furin-diabetes is related to an increase of Furin and this may accelerate the replication of the virus

b) An increase of Interleukin-6 - which is increased in diabetes and can facilitate the infection of COVID-19

c) An increase in ACE2 expression-which may predispose a person with diabetes to a SARS-CoV-2 infection

d) Impaired T-Cell function-lymphocytopenia was detected in a patient infected with COVID-19 [41].

$\mathrm{R}_{0}$ is an important index in epidemiology. The transmission modes, $\mathrm{R}_{0}$, and case fatality rates of some infectious diseases are shown in Table $4[37,42,43]$. Cases and case fatality rates of COVID-19 vary with time, countries, and regions. As of September 15,2020 , the case fatality rate in the world is from $0.2 \%$ to $29.0 \%$ according to the data reported by Johns Hopkins University \& Medicine, USA (https://coronavirus.jhu.edu/data/mortality). Table 5 [38] further compares the transmission of the three CoVs: MERSCoV, SARS-CoV-1, and SARS-CoV-2. Some patients were treated by an acute care team, screened to check whether they were infected with COVID-19, and re-directed to self-isolation (when necessary) or the emergency department. This helped reduce the virus spread to healthcare providers. Face-to-face evaluations were restricted to reduce patient exposure to the hospital and healthcare provider exposure to patients who are infected with COVID-19, keeping Personal Protective Equipment (PPE) for medical professionals in the front line [44]. It is necessary to estimate the serial interval that is the period from the illness onset of a primary case to that of a secondary case. This helps understand the virus transmission and the turnover of case generation. The serial interval of COVID-19 is close to or less than the median of its incubation value, suggesting that the infection of SARS-CoV-2 results in a rapid transmission cycle. An estimate of the median of the serial interval of COVID-19 is four days. A considerable ratio of secondary transmission could happen prior to the illness onset. The serial interval value of COVID-19 is also less than that of SARS [45].

Table 4: $\mathrm{R}_{0}$, transmission modes, and case fatality and case fatality rates of some infectious diseases.

\begin{tabular}{|c|c|c|c|}
\hline Diseases & $\begin{array}{c}\text { Transmission } \\
\text { Modes }\end{array}$ & $\mathbf{R}_{\mathbf{0}}$ & $\begin{array}{c}\text { Case Fatality } \\
\text { Rates (\%) }\end{array}$ \\
\hline Measles & Airborne & $12.0-18.0$ & 0.3 \\
\hline COVID-19 & $\begin{array}{c}\text { Airborne droplet } \\
\text { (main mode) }\end{array}$ & $2.3-5.5$ & $0.2-29.0$ \\
\hline HIV/AIDS & $\begin{array}{c}\text { Blood and body } \\
\text { fluids }\end{array}$ & $2.0-5.0$ & $\begin{array}{c}80.0, \text { without } \\
\text { therapy }\end{array}$ \\
\hline
\end{tabular}

\begin{tabular}{|c|c|c|c|}
\hline SARS & $\begin{array}{c}\text { Airborne droplet } \\
\text { (main mode) }\end{array}$ & $2.0-5.0$ & 9.6 \\
\hline Ebola & $\begin{array}{c}\text { Blood and body } \\
\text { fluids }\end{array}$ & $1.5-2.5$ & 70 \\
\hline $\begin{array}{c}\text { H1N1 Influenza A } \\
\text { (Swine flu 2009) }\end{array}$ & $\begin{array}{c}\text { Infected droplets } \\
\text { (by coughing or } \\
\text { sneezing) }\end{array}$ & $1.4-1.6$ & 0.02 \\
\hline MERS & Close contact & $0.3-0.8$ & 34.0 \\
\hline
\end{tabular}

Table 5: Comparison of MERS-CoV, SARS-CoV-1, and SARSCoV-2 in transmission.

\begin{tabular}{|c|c|c|c|}
\hline Transmission & MERS-CoV & SARS-CoV-1 & SARS-CoV-2 \\
\hline Respiratory droplets & Yes & Yes & Yes \\
\hline Aerosol & Yes & Yes & High probability \\
\hline Fomites, contact & No & No & Yes \\
\hline Orofecal & No & Yes & Yes \\
\hline Human-to-human & Limited & Yes & Yes \\
\hline Zoonotic & Sporadic & Sporadic & Yes \\
\hline Nosocomial & Yes & Yes & Yes \\
\hline Cell entry receptor & DPP-4/CD26 & ACE2 & ACE2 \\
\hline
\end{tabular}

\section{Testing of COVID-19}

An initial screening for COVID-19 is often used and an examination using Computed Tomography (CT) is often needed as an auxiliary diagnosis.

This diagnosis is then validated by the result of RT-PCR using the Nucleic Acid Amplification Test (NAAT) of blood specimens or the respiratory tract, but there is limitation in this method:

a) Only a positive test can be performed, the progression and severity of COVID-19 cannot be obtained, on the other hand, imaging technology based on CT can display the progression of COVID-19.

b) The detection rate is low if the viral load is low, which leads to a false-negative result.

c) The supply of reagents often does not meet requirements.

d) It often takes one (1) day or even longer to get the result after testing, sometimes as long as 14 days if the labs are backed up.

Therefore, CT imaging is strongly recommended. When a person has a negative NAAT but a positive result of CT imaging, the person still needs to be isolated and get medical treatment as early as possible [46]. Recently, Abbott labs unveiled a new series of tests which use a gentle nasal swab and five reagent drops onto a cartridge to give a rapid positive or negative result within 15 minutes. These tests have proven to be change agents for COVID-19 testing and are $99 \%$ accurate. The USA has rolled these tests out to nursing homes, assisted living facilities, schools, etc., where the most vulnerable or highest segment of positive individuals may be. 


\section{Vaccines and Therapeutics for COVID-19}

SARS-CoV-2 utilizes ACE2 as the entry receptor of invading target cells. Cryoelectronic microscopy structures of the spike glycoprotein of SARS-CoV-2 indicate the potential to develop therapeutics and vaccines [5]. Developing vaccines against SARS-CoV-2 is an urgency. Many countries are in the process of developing vaccines. The USA has four vaccines currently in Stage 3 Development which is the human trial stage. The USA President has approved a rapid development program for vaccines where the drug company will deliver 100 million vials of vaccine the very moment the vaccine is approved by the Food and Drug Administration (FDA). Moderna, Pzfizer, and Johnson \& Johnson are currently conducting trials with more than 30,000 volunteers per trial. The United States is set to roll out a vaccine by the end of 2020 if not before. Table 6 [47] list the disadvantages and advantages of a few vaccine strategies. Attenuated and inactivated virus vaccines are advisable.

Table 6: Disadvantages and advantages of various vaccine strategies.

\begin{tabular}{|c|c|c|}
\hline Vaccine strategies & Disadvantages & Advantages \\
\hline $\begin{array}{l}\text { Attenuated virus } \\
\text { vaccines }\end{array}$ & $\begin{array}{l}\text { Possible phenotypic or } \\
\text { genotypic reversion; } \\
\text { enable some diseases }\end{array}$ & $\begin{array}{l}\text { Fast development; } \\
\text { induce high immune } \\
\text { responses }\end{array}$ \\
\hline $\begin{array}{l}\text { Inactivated virus } \\
\text { vaccines }\end{array}$ & $\begin{array}{l}\text { Possible inappropriate } \\
\text { for highly } \\
\text { immunosuppressed } \\
\text { individuals }\end{array}$ & $\begin{array}{c}\text { Safety; easy to prepare; } \\
\text { high-titer neutralizing } \\
\text { antibodies }\end{array}$ \\
\hline DNA vaccines & $\begin{array}{c}\text { Repeated doses may } \\
\text { cause toxicity; lower } \\
\text { immune responses in } \\
\text { humans }\end{array}$ & $\begin{array}{c}\text { High safety; easy to } \\
\text { develop; high-titer } \\
\text { neutralizing antibodies }\end{array}$ \\
\hline Viral vector vaccines & $\begin{array}{l}\text { Possibly present pre- } \\
\text { existing immunity }\end{array}$ & $\begin{array}{l}\text { Safety; induce high } \\
\text { cellular and humoral } \\
\text { immune responses }\end{array}$ \\
\hline
\end{tabular}

Immunotherapy is an effective therapeutic option of intervention against COVID-19. Primary approaches, for example, utilizing convalescent plasma therapy and immunoglobulins have achieved better clinical effects for patients with COVID-19 [48]. Human coronaviruses (HCoVs), for example, SARS-CoV-2, lead in global pandemics. There have been no certified drugs developed to work against novel SARS-CoV-2. Drug repurposing is a strategic approach to effective drug discovery based on available drugs. There are currently 16 prospective repurposable anti-HCoV drugs (e.g., sirolimus, mercaptopurine, and the hormone melatonin) have been prioritized based on the network proximity analysis of drug targets [49]. Mutations of SARS-CoV-2 have occurred naturally and easily, however, theories are that while the SARS-CoV-2 is more contagious and easier to spread, its mortality rate has decreased. For example, while the public typically understand that the most vulnerable populations to SARS-CoV-2 are those individuals with comorbidities and those who are over the age of 70 . However, the survival rate of individuals ages $18-40$ has increased to $99.7 \%$ and for the elderly over age 70 with or without comorbidities, survival rates have increased to $94 \%$. The knowledge of SARS-CoV-2 virology has helped to find potential drug targets, which have also increased survival rates across all populations. Various antivirals that were employed to fight MERS-CoV, MERS-CoV-1, and even influenza have been assessed to determine their efficacy in patients infected with COVID-19. Remdesivir, Lopinavir, Ritonavir, and Oseltamivir can block the COVID-19 infection [3,50,51] and Remdesivir can improve the mortality rate by as much as $35 \%$. A combination of steroids such as dexamethasone, solumedrol, etc., when combined with Remdesivir also improves the survival rate. Convalescent plasma exchange increases survival by as much as $35 \%$. These are highly sought therapeutics with more being developed. Some drug companies are currently working on antibody treatments to give to severely ill COVID-19 patients.

Traditional Chinese medicine (TCM) has also helped to treat patients with COVID-19 in China, TCM schemes were incorporated in guidelines of diagnosing and treating COVID-19 and TCM professionals participated in the rescue process of COVID-19 in China. Acupuncture, Chinese patent medicine, a feature therapy of TCM, etc. were used. TCM has its own features, for example, a balance between Yang and Yin, holistic concepts, personal treatments based on the syndromes of individuals, and improving the body's capability in eliminating pathogenic factors. The treatment practice and experiences of COVID-19 have demonstrated that an early intervention based on TCM is a significant approach to delaying the disease progression, shortening the course of disease, and decreasing the mortality rate. TCM not only inhibits viruses, but also blocks infections and regulates immune responses [52].

\section{Discussion}

Since coronaviruses may have frequent recombination and rapid mutation, will these kinds of activities produce novel strains with increased pathogenicity and transmissibility? What is the role played by point mutation and recombination during the evolution of SARS-CoV-2? [53]. The origin of this novel CoV deserves deep study or investigations and some important issues need to be addressed:

a) The molecular mechanism of the inter-species transmission of SARS-CoV-2

b) The similarities as well as distinct features of this mechanism compared to MERS-CoV and SARS-CoV-1 [53].

Platelet count is an easily available and simple biomarker that is independently related to a risk of mortality and disease severity in an Intensive Care Unit (ICU). A low platelet count is related to an increased risk of mortality or severity of COVID-19 patients; therefore, it can be regarded as a clinical parameter or indicator of a more severe illness during hospitalization [54]. Implementing a telemedicine system with a focus on meeting the need of low-acuity patients with disease exposure concerns can mitigate and prevent 
overcrowding in an emergency department, urgent care clinic, or primary care clinic while offering the guidance and reassurance that patients request. Telemedicine systems can greatly enhance the treatment, triage, and coordination of care for patients infected with COVID-19, especially in low resource regions [55]. Although therapeutics have improved and improvement in the survival rates of patients treated with the available therapeutics have increased, the rapid transmission of COVID-19, mass quarantine measures, and a lack of vaccines have caused some mental health problems, e.g., sleep problems, anxiety, fear, depression, drug abuse increases, and suicide for the public, COVID-19 patients, and some healthcare professionals. Thus, it is necessary to establish suitable health services to mitigate the risk of psychiatric comorbidities. A joint effort of implementing international collaboration is especially necessary and significant to resolve mental health challenges due to the pandemic of COVID-19 [56]. Artificial intelligence (AI) has been used worldwide in fighting COVID-19. Main applications include [57]:

a) Help diagnose infected cases with imaging technology, for example, Magnetic Resonance Imaging (MRI) and CT, quickly analyze abnormal symptoms, and fulfill early detection and diagnosis.

b) Create a framework or platform for automatic monitoring, prediction, and treatment of COVID-19. Some research has been done using neural networks to extract features of COVID-19.

c) Help drug delivery design and development, fast vaccine development and treatment, and clinical trials during the vaccine development.

\section{Conclusion}

COVID-19 has had a rapid spread globally. It has been a worldwide pandemic partly due to some similarities to other viral diseases such as influenza, MERS, SARS, and EVD; therefore, many people were not aware of its substantial risk in the early stages of this newly emerging disease. It has a longer median incubation, a longer period of infectivity, higher case-fatality rates with comorbidities, and higher asymptomatic viral loads. Fever happens in only $43.8 \%$ of patients with COVID-19 on an initial manifestation. The original host of SARS-CoV-2 has not been confirmed. Vaccines and Therapeutics for COVID-19 are still in the process of development, although many therapeutics exist and have proven to increase survival rates. The control of pre-symptomatic or asymptomatic transmissions, the development of vaccines and antiviral drugs, difficulty in international collaboration due to politics, medical supply chains and management, etc. have been challenges in fighting COVID-19. Telemedicine during COVID-19, Internet of Things (IoT) for real-time monitoring and data capture, Big Data analytics for COVID-19 cases and prediction, AI applications in COVID-19, etc. can be future research topics.

\section{Acknowledgement}

Authors thank Technology \& Healthcare Solutions, Mississippi, USA for technical support.

\section{Conflicts of Interest}

No.

\section{References}

1. Siordia Jr JA (2020) Epidemiology and clinical features of COVID-19: A review of current literature. Journal of Clinical Virology 127: 104357.

2. Ou X, Liu Y, Lei X, Li P, Mi D (2020) Characterization of spike glycoprotein of SARS-CoV-2 on virus entry and its immune cross-reactivity with SARS-CoV. Nature communications 11(1): 1-12.

3. Shereen MA, Khan S, Kazmi A, Bashir N, Siddique R (2020) CoVID-19 infection: Origin, transmission, and characteristics of human coronaviruses. Journal of Advanced Research 24: 91-98.

4. Wu C, Liu Y, Yang Y, Zhang P, Zhong W (2020) Analysis of therapeutic targets for SARS-CoV-2 and discovery of potential drugs by computational methods. Acta Pharmaceutica Sinica B 10(5): 766-788.

5. Walls AC, Park YJ, Tortorici MA, Wall A, McGuire AT (2020) Structure, function, and antigenicity of the SARS-CoV-2 spike glycoprotein. Cell 181(2): 281-292.

6. Baglivo M, Baronio M, Natalini G, Beccari T, Chiurazzi P (2020) Natural small molecules as inhibitors of coronavirus lipid-dependent attachment to host cells: a possible strategy for reducing SARS-COV-2 infectivity? Acta Biomed 91(1): 161-164.

7. Marty AM, Jones MK (2020) The novel coronavirus (SARS-CoV-2) is a one health issue. One Health 9:100123.

8. Liu J, Zhou J, Yao J, Zhang X, Li L (2020) Impact of meteorological factors on the COVID-19 transmission: A multi-city study in China. Science of the Total Environment 726: 138513.

9. Ikonen N, Savolainen Kopra C, Enstone JE, Kulmala I, Pasanen P (2018) Deposition of respiratory virus pathogens on frequently touched surfaces at airports. BMC infectious diseases 18(1): 1-7.

10. Witcher R, Tracy J, Santos L, Chopra A (2019) Outcomes and Adverse Effects with Peramivir for the Treatment of Influenza H1N1 in Critically Ill Pediatric Patients. The Journal of Pediatric Pharmacology and Therapeutics 24(6): 497-503.

11. Singanayagam A, Zhou J, Elderfield RA, Frise R, Ashcroft J (2020) Characterising viable virus from air exhaled by H1N1 influenza-infected ferrets reveals the importance of haemagglutinin stability for airborne infectivity. PLoS pathogens 16(2): e1008362.

12. Ostrowsky J, Arpey M, Moore K, Osterholm M, Friede M (2020) Tracking progress in universal influenza vaccine development. Current Opinion in Virology 40: 28-36.

13. Krietsch Boerner L (2020) The Flu Shot and the Egg. ACS Cent. Sci 6: 89-92.

14. Van Poelvoorde LA, Saelens X, Thomas I, Roosens NH (2020) NextGeneration Sequencing: An Eye-Opener for the Surveillance of Antiviral Resistance in Influenza. Trends in biotechnology 38(4): 360-367.

15. Habibzadeh P, Stoneman EK (2020) The novel coronavirus: a bird's eye view. The international journal of occupational and environmental medicine 11(2): 65-71.

16. Hasöksüz M, Kiliç S, Saraç F (2020) Coronaviruses and SARS-CoV-2. Turkish Journal of Medical Sciences 50(SI-1): 549-556.

17. Thiel V, Ivanov KA, Putics A, Hertzig T, Schelle B (2003) Mechanisms and enzymes involved in SARS coronavirus genome expression. Journal of General Virology 84(9): 2305-2315. 
18. Rabenau HF, Cinatl J, Morgenstern B, Bauer G, Preiser W (2005) Stability and inactivation of SARS coronavirus. Medical microbiology and immunology 194(1-2): 1-6.

19. Booth TF, Kournikakis B, Bastien N, Ho J, Kobasa D (2005) Detection of airborne severe acute respiratory syndrome (SARS) coronavirus and environmental contamination in SARS outbreak units. The Journal of infectious diseases 191(9): 1472-1477.

20. Hoffmann M, Kleine Weber H, Krüger N, Mueller MA, Drosten C (2020) The novel coronavirus 2019 (2019-nCoV) uses the SARS-coronavirus receptor ACE2 and the cellular protease TMPRSS2 for entry into target cells. BioRxiv. Jan 1: 1-23.

21. Rahman A, Sarkar A (2019) Risk factors for fatal middle east respiratory syndrome coronavirus infections in Saudi Arabia: analysis of the WHO Line List, 2013-2018. American journal of public health 109(9): 12881293.

22. Sayed AS, Malek SS, Abushahba MF (2020) Seroprevalence of Middle East Respiratory Syndrome Corona Virus in dromedaries and their traders in upper Egypt. The Journal of Infection in Developing Countries 14(2): 191-198.

23. Al Mutair A, Ambani Z (2020) Narrative review of Middle East respiratory syndrome coronavirus (MERS-CoV) infection: updates and implications for practice. Journal of International Medical Research 48(1): 1-6.

24. Rabbani SA, Mustafa F, Mahtab A (2020) Middle East Respiratory Syndrome (MERS): Awareness among Future Health Care Providers of United Arab Emirates. International Journal of Medicine and Public Health 10(1): 8-13.

25. Altamimi A, Ahmed AE (2020) Climate factors and incidence of Middle East respiratory syndrome coronavirus. Journal of infection and public health 13(5): 704-708.

26. Zumla A, Alagaili AN, Cotten M, Azhar EI (2016) Infectious diseases epidemic threats and mass gatherings: refocusing global attention on the continuing spread of the Middle East Respiratory syndrome coronavirus (MERS-CoV). BMC medicine 14(1): 1-4.

27. Durham ND, Howard AR, Govindan R, Senjobe F, Fels JM (2020) RealTime Analysis of Individual Ebola Virus Glycoproteins Reveals PreFusion, Entry-Relevant Conformational Dynamics. Viruses 12(1): 103.

28. Rojas M, Monsalve DM, Pacheco Y, Acosta-Ampudia Y, Ramírez-Santana C (2020) Ebola virus disease: An emerging and re-emerging viral threat. Journal of autoimmunity 106: 102375 .

29. Kellerborg K, Brouwer W, van Baal P (2020) Costs and benefits of early response in the Ebola virus disease outbreak in Sierra Leone. Cost Effectiveness and Resource Allocation 18(1): 1-9.

30. Ward MD, Kenny T, Bruggeman E, Kane CD, Morrell CL (2020) Early detection of Ebola virus proteins in peripheral blood mononuclear cells from infected mice. Clinical proteomics 17(1): 1-11.

31. Hendricks K, Parrado MG, Bradley J (2020) Opinion: An Existing Drug to Assess In Vivo for Potential Adjunctive Therapy of Ebola Virus Disease and Post-Ebola Syndrome. Frontiers in Pharmacology 10: 1691.

32. Yam D, Aluisio AR, Perera SM, Peters JL, Cho DK (2020) Association between multivitamin supplementation and mortality among patients with Ebola virus disease: An international multisite cohort study. African Journal of Emergency Medicine 10(1): 23-29.

33. El Zowalaty ME, Järhult JD (2020) From SARS to COVID-19: A previously unknown SARS-CoV-2 virus of pandemic potential infecting humansCall for a One Health approach. One Health 9: 100124.

34. Zhou P, Yang XL, Wang XG, Hu B, Zhang L (2020) A pneumonia outbreak associated with a new coronavirus of probable bat origin. Nature 579(7798): 270-273.

35. Seo G, Lee G, Kim MJ, Baek SH, Choi M (2020) Rapid detection of COVID-19 causative virus (SARS-CoV-2) in human nasopharyngeal swab specimens using field-effect transistor-based biosensor. ACS Nano14(4): 5135-5142.

36. Rothan HA, Byrareddy SN (2020) The epidemiology and pathogenesis of coronavirus disease (COVID-19) outbreak. Journal of autoimmunity 109: 102433.

37. Kakodkar P, Kaka N, Baig MN (2020) A comprehensive literature review on the clinical presentation, and management of the pandemic coronavirus disease 2019 (COVID-19). Cureus 12(4): e7560.

38. Singh A, Shaikh A, Singh R, Singh AK (2020) COVID-19: From bench to bed side. Diabetes \& Metabolic Syndrome: Clinical Research \& Reviews 14(4): 277-281

39. Han Q, Lin Q Jin S, You L (2020) Coronavirus 2019-nCoV: A brief perspective from the front line. Journal of Infection 80(4): 373-377.

40. Cheng MP, Papenburg J, Desjardins M, Kanjilal S, Quach C (2020) Diagnostic testing for severe acute respiratory syndrome-related coronavirus-2: A narrative review. Annals of internal medicine 172(11): 726-734.

41. Singh AK, Gupta R, Ghosh A, Misra A (2020) Diabetes in COVID-19: Prevalence, pathophysiology, prognosis and practical considerations. Diabetes \& Metabolic Syndrome: Clinical Research \& Reviews 14(4): 303-310.

42. Liu CX (2020) Pay attention to situation of SARS-CoV-2 and TCM advantages in treatment of novel coronavirus infection. Chinese Herbal Medicines 12(2): 97-103.

43. Chen J (2020) Pathogenicity and transmissibility of 2019-nCoV- a quick overview and comparison with other emerging viruses. Microbes and infection 22(2): 69-71.

44. Kavoor AR, Chakravarthy K, John T (2020) Remote consultations in the era of COVID-19 pandemic: Preliminary experience in a regional Australian public acute mental health care setting. Asian Journal of Psychiatry 51: 102074.

45. Nishiura H, Linton NM, Akhmetzhanov AR (2020) Serial interval of novel coronavirus (COVID-19) infections. International journal of infectious diseases 93: 284-286.

46. Dai WC, Zhang HW, Yu J, Xu HJ, Chen H (2020) CT imaging and differential diagnosis of COVID-19. Canadian Association of Radiologists Journal 71(2): 195-200.

47. Shang W, Yang Y, Rao Y, Rao X (2020) The outbreak of SARS-CoV-2 pneumonia calls for viral vaccines. npj Vaccines 5(1): 1-3.

48. Amin Jafari A, Ghasemi S (2020) The possible of immunotherapy for COVID-19: A systematic review. International Immunopharmacology 83: 106455 .

49. Zhou Y, Hou Y, Shen J, Huang Y, Martin W (2020) Network-based drug repurposing for novel coronavirus 2019-nCoV/SARS-CoV-2. Cell discovery 6(1): 1-8.

50. Cao YC, Deng QX, Dai SX (2020) Remdesivir for severe acute respiratory syndrome coronavirus 2 causing COVID-19: An evaluation of the evidence. Travel Medicine and Infectious Disease 35: 101647.

51. Sanders JM, Monogue ML, Jodlowski TZ, Cutrell JB (2020) Pharmacologic treatments for coronavirus disease 2019 (COVID-19): a review. Jama 323(18): 1824-1836.

52. Ren JL, Zhang AH, Wang XJ (2020) Traditional Chinese medicine for COVID-19 treatment. Pharmacological research 155: 104743.

53. Xu Y (2020) Unveiling the Origin and Transmission of 2019-nCoV. Trends in microbiology 28(4): 239-240.

54. Lippi G, Plebani M, Henry BM (2020) Thrombocytopenia is associated with severe coronavirus disease 2019 (COVID-19) infections: a metaanalysis. Clinica Chimica Acta 506: 145-148. 
55. Rockwell KL, Gilroy AS (2020) Incorporating telemedicine as part of COVID-19 outbreak response systems. Am J Manag Care 26(4): 147-148.

56. Xiang YT, Jin Y, Cheung T (2020) Joint international collaboration to combat mental health challenges during the coronavirus disease 2019 pandemic. JAMA psychiatry 10: 1-2.

ISSN: 2574-1241

DOI: $10.26717 /$ BJSTR.2020.31.005071

Lidong Wang. Biomed J Sci \& Tech Res

(c) (P) This work is licensed under Creative

Submission Link: https://biomedres.us/submit-manuscript.php
57. Vaishya R, Javaid M, Khan IH, Haleem A (2020) Artificial Intelligence (AI) applications for COVID-19 pandemic. Diabetes \& Metabolic Syndrome: Clinical Research \& Reviews 14(4): 337-339.

$\begin{array}{ll}\text { BIOMEDICAL } & \text { Assets of Publishing with us } \\ \text { RESEARCHES } & \text { - Global archiving of articles } \\ & \text { - Immediate, unrestricted online access } \\ & \text { - Rigorous Peer Review Process } \\ & \text { - Anttps://biomedres.us/ }\end{array}$

